\title{
Author Correction: The global distribution of tetrapods reveals a need for targeted reptile conservation
}

Uri Roll, Anat Feldman, Maria Novosolov, Allen Allison, Aaron M. Bauer, Rodolphe Bernard, Monika Böhm, Fernando Castro-Herrera, Laurent Chirio, Ben Collen, Guarino R. Colli, Lital Dabool, Indraneil Das, Tiffany M. Doan, Lee L. Grismer, Marinus Hoogmoed, Yuval Itescu, Fred Kraus, Matthew LeBreton, Amir Lewin, Marcio Martins, Erez Maza, Danny Meirte, Zoltán T. Nagy, Cristiano de C. Nogueira, Olivier S. G. Pauwels, Daniel Pincheira-Donoso, Gary D. Powney, Roberto Sindaco, Oliver Tallowin, Omar Torres-Carvajal, Jean-François Trape, Enav Vidan, Peter Uetz, Philipp Wagner, Yuezhao Wang, C David L Orme, Richard Grenyer and Shai Meiri

Correction to: Nature Ecology \& Evolution https://doi.org/10.1038/s41559-017-0332-2 (2017); published online 9 October 2017.

In the version of this Article originally published, grant no. 2015/20215-7 for C.N. was omitted from the Acknowledgements section. This has now been corrected in all versions of the Article. 